\title{
THE IMPORTANCE OF A FOLLOW-UP SYSTEM FOR OBSTETRIC PATIENTS*
}

\author{
By Geonge W. Kosmak, M.D., F.A.C.S., New York, N. Y. \\ Attending Surgeon, Lying-In Hospital, New York, N. Y.
}

$\mathrm{I}^{\mathrm{N}}$ $N$ these days of "health conservation measures" the question may well be asked whether the recently delivered mother in eithor private or hospital practice is accorded as much attention in a follow-up sense as a patient recovering from medical or surgical illness. It is now commonly regarded as essential to the proper functioning of a hospital that each patient be kept under observation during a definite period after discharge and to report for examination at stated intervals or be visitcd by the social scrvice worker. Thus, not only the immediate but the later results of treatment are known and can be acted upon. In surgical cases, particularly, the final physiologic, as well as the anatomic outcome of the particular operation is insisted upon as a matter of record and study. Does this development in modern methods apply with equal force to obstetric patients? Is proper care extended for a sufficient length of time after delivery to obviate the posible production of pathologic lesions and to provide for their correction if noted? Laudable and constantly increasing attention has been accorded by malernity institutions to provisions for antepartum eare, both for the sake of the mother and her unborn child. A thorough physical examination of the prospective mother is urged, and with blood pressure observations, urinalyses, pelvic measurements, ete., regarded as essential in every well ordered maternity. But once the interest and excitement attendant upon delivery is over, the patient in many cases is discharged with a cursory examination at the end of a stated period and little more attention paid to her. This also applies in many instances to private patients. There is no reason why this condition of affairs should be allowed to exist. Although accepted as physiologic, the process of parturition verges so closely upon the pathologic, that it is often difficult to draw a line of demarcation. Moreover, the process of involution is by no means complete when the patient is able to be out of bed, and complications may develop and escape notice if a pelvic examination is not made after the usual period of two weeks in the hospital. We may briefly inquire at this point into these possibilities and then discuss means for their correction. The usual method of postpartum examination when it is conducted, takes note of the breasts, the degree of uterine involution as determined by the lochia, the size of the utcrus, its consistency and mobility, the state of the adnexal organs, the condition of the cervix and pcrinoum. If the results of this examination are fairly satisfactory, the patient is ordinarily discharged and in many cases not seen again unless complica-

"Read at the Forty-fifth Annual Meeting of the Anerican Gynecological Suciety, Chicago, May 24-26, 1920 . 
tions develnp. Let us consider these points somewhat more in detail, although we may be accused of dealing with trite and elementary facts.

The involution of the uterus as already stated, is usually gauged by the size, consistency, and character of the lochial discharge. Ordinarily the bright red lochia should disappear after the eighth or ninth day, but inquiry will often clicit the fact that in a great many cases the bright discharge reappears after the patient has been up for several days. A bloody discharge means a halt in the process of uterine involution and above all requires rest in bed with the possible administration of oxytocic measures. A considerable amount of blood may be lost unless this condition is promptly checked, and not only does the patient suffer from this, but the congested uterus is more apt to be displaced either downward or backward. As concerns malposition of the uterus we often find an apparently normal anteversion at the end of ten or twelve days converted into retroversion if the patient be examined again four to six weeks later. This is usually accompanied by enlargement and congestion, which have probably contributed to the displacement. If appropriate measures are not immediately instituted, involution is further retarded and the uterus may remain permanently in this abnormal position. At this time postural treatment is indicated, including the knee-chest position, the so-called kangaroo walk, and having the patient avoid lying on her back. The bowels must also be kept open and oxytocics administered to reduce the size of the uterus. There is no value in the use of pessaries at this time and they should not be employed until the uterus has involuted properly and has been returned to its normal anteverted position. I have recently observed several cases in which retroversion pessaries have failed to retain the enlarged uterus. The possibility of these malpositions shows the necessity of making regular pelvic examinations at the end of the first and second month; otherwise the condition will be overlooked.

Perineal lacerations should also be observed at regular intervals. I have seen a perineum only partially healed at the end of the tenth day, yet the patient was discharged from the care of the hospital and physician. The process of repair varies with the general condition of the patient. In some it takes place quickly and a good result is present at the end of a week. In others a failure occurs because of the inherently poor character of the tissues or because of extensive trauma. In the former there is nothing to do exccpt to reoperate al a later time. Tf infection has resulted or sloughing in the case of bruised tissues, operation must be postponed. Secondary perineorrhaphy at the end of ten days or two weeks is often followed by good results where the lochial discharges are fairly clean, but in the presence of a continuous foul lochia such intermediate operations had best be deferred and the wound allowed to heal by granulation. There is another class of perineal lacerations that must be noted, namely, those involving the sphincter ani that have not been diagnosed immediately after delivery. Several cases have come to my notice in which after a week or ten days with apparently normally functioning sphineter ani muscles, incontinence followed and examination showed that an attenuated sphincter was either torn or exposed in a perineal tear that had failed to heal. Such cases can usually be satisfactorily operated on at the end of two 
weeks. Episiotomy, either lateral or central, provides for better healing in many cases and while I hesitate to recommend routine operation, I think that it serves a good purpose in those cases where a rigid outlet impedes the extension and delivery of the head. Lateral episiotomy has the advantage of being somewhat further away from the course of the lochial discharges, but is more difficult to repair and the resulting sear may be morc painful than in the central variety.

The importance of unhealed cervical lacerations has been underestimated. The minor degrees undoubtedly heal without much disturbance, but in many cases the bilateral tears fail to unite, and considerable eversion of the anterior and posterior lips results. This exposes the lining membrane of the cervical canal and so-called "erosions" of the cervix usually follow. Unhealed lacerations of the cervix offer an opportunity for the ahsorption of septic material that undoubtedly in a great many cases leads to milder grades of infection involving the cellular tissue in the lower portions of the broad ligaments on either side and also the area back of the uterus included in the region of the sacrouterine ligaments. The course of this infection is insidious but is probably an important factor in producing the backache which so many women complain of during the first year after childbirth. A careful examination of postpartum cases within the first few months after delivery has demonstrated quite elearly to me that this is a complication to be reckoned. It may be avoided to some degree by treating these so-called ulcerated areas as soon after delivery as possible by appropriate local measures. In a series of hospital cases which I examined recently, every lacerated cervix was exposed through a bivalve speculum and the raw surfaces swabbed with nitrate of silver or iodine. The patients were then directed to return to the hospital at least once or twice a week for further treatment. I have also followed this out in my private cases and I think with good results in so far as a limited number seem to have been free from further complicating symptoms. The immediate repair of cervical injuries might be referred to at this point. Some years ago at the Lying-in Hospital every primiparous cervix which was lacerated was immediately sutured, but we found a marked rise of temperature in so many cases that we discontinued the procedure and limited suture of the cervix to the advanced degrees where it was necessary to control hemorrhage. I do not believe, however, that in the majority of cases proper normal healing of the cervix results, as we find a great many instances in which the marked eversion of the lips already referred to shows that union has failed to take place.

The abnormalities noted include the commoner postpartum lesions to which others may be added, such as mild degrees of pelvic inflammatory processes, particularly of the tube; involvement of the urinary tract, urethritis, trigonitis, cystitis, and pyelitis, which often are not disclosed until several weeks after labor; relaxation or inflammation of the pclvic joints; phlebitis of the pelvic vcins, and finally among the morc unusual conditions, degenerative changes in fibroid uteri or torsion of pedunculated ovarian cysts. Any one of the above may escape notice or may not have been present at the usual time of antepartum examination. In many instances the oceurrcnee of such lesions 
may not have been preventahle, but whether or no, timely recognition and treatment will at any rate reduce the invalidism which often follows in their wake.

In the hope of stimulating a more general interest in a follow-up system, particularly for institutional patients, the writer recently undertook the circulation of a questionnaire to ohtain some information as to the actual methods which had been employed by various maternity hospitals. (A copy of the questionnaire is appended.*) A total of over 60 were sent out and replies were received from 48 American institutions.

An analysis of the results shows that 36 out of 48 have some sort of a follow-up system for their obstetric patients, including regularly organized clinical facilities in charge of the attending staff. In the majority (28) the patients only return if abnormalities develop, but are not directed to report at stated intervals after delivery. In 31 institutions a social service system is maintained by nurses for following their cases and some provision is made for babies in 37 institutions. Provision for the treatment of gynecologic conditions noted after labor is made in 37 maternity hospitals and in 11 they are referred elsewhere.

The admission is made by practically every one who answered the questionnaire that a follow-up system for obstetric patients is not only desirable, but necessary. In this comnection the difficulties attending the institution of such a system for hospital patients must be acknowledged. A woman who is busy with the care of her family is not always able to come back for subsequent examinations unless the condition is serious enough to compel her attendance. This applies particularly to patients that live a considerable distance from the hospital, but should not apply to private patients who ought to be encouraged to visit their physician at least once a month for three months subsequent to delivery. If this is not feasible, arrangements might be made with a local physician. In the case of hospital paticnts the follow-up system is favored by the employment of visiting nurses, just as is now done by surgical, medical and gynecologic services. A number of institutions have already adopted this plan and if the visiting nurse finds any gross abnormalities, a hospital physician visits the case, or the patient is directed to an institution. The organization of so-called "maternity center associations," as in New York City, may be of great value in the development of this scheme, especially as their clinies are ordinarily located nearer the patient's home than the hospital in which she was confined. Co-operation and co-ordination could, it seems to me, bring

\section{*QUESTIONNAIRE}

AN INQUIRY INIU A FOLLOW-UP SYSTEM FOR OBSTETRICAE PATIENTS

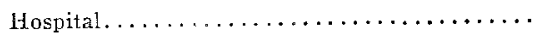

Reporter................................ delivery is the pucrperal paticnt discharged?

1. On what diay dire patient directed to come back to the hospital at a stated time, or only if abnormalities develop?

3. Is there any definitely organized postpartum clinic provided on certain days to which patients may apply?

4. Under whose charge is the clinic-attending surgeon or house staff?

5. Do attending surgeons see their cases at definite periods after discharge?

6. Are notes taken of such subsequent visits?

7. Have you dny method of following up cases at their hounes by social service workers or nurses?

8. Have you any information based on your cases of the proportion of postpartum women examined in whom the following conditions have been noted: Malpositions of the uterus, exudates, cervical erosions, lacerations, condition of perineum and results of perineorrhaphy?

9. In the event of lesions being found, what facilities are provided for their treatment in the same or other institution?

10. Are'such operations done by your attending staff? 11. Are sleps taken to insure proper supervision of the baby by visiting nurses or reference to pediatric
clinics?
} 
about a working agreement in which the function of the maternity center could be increased in a most valuable fashion and the hospital perhaps saved a certain amount of trouble and expense.

A regularly organized postpartum elinic should be part of every maternity hospital equipment. To this clinic every mother should be directed to come at stated intervals if possible. At such subsequent visits abnormalities which have developed since the discharge of the patient from the hospital can be detected and appropriate treatment instituted. Patients that present gross lesions, such as unhealed lacerations, uterine displacements, pelvic tumors, and other conditions, could be kept under observation and treated surgically if the occasion demanded. It also seems desirable that gynecologic operations be done either in the same or related institutions so that the patient remain under the observation of the same attending staff through the entire period. Such postpartum, or we may call them gynecologic clinics, should be under the direct supervision of attending surgeons, and, if possible, especially in the cases of operative deliveries, the operator personally ought to wake the follow-up observations.

Admitting the value and necessity of adequate observations on postpartum cases, what may be considered a practical scheme for developing this for institutional or private patients? The return of every recently delivered mother to a state of health at least approximating that before her pregnancy, if not surpassing it, should be the aim of every maternity service and also every physician who takes care of obstetric eases. It is difficult to estimate how large a proportion of invalidism in women who have borne children can be traced directly to abnormalities of their pregnancy, labor, or puerperium, but it cannot be denied that the proportion is a considerable one. The tendency of modern medicine has been towards prevention. Can it be said that this effort has been sufficiently developed in the handling of woman's most important function in life? The results of childbearing cannot be expected to leave every woman in as good condition as she was previous to parturition, but an attempt should be made to diminish the proportion of invalidism as much as possible. I belicve that this can only be done by conecrted effort; by impressing, on the one hand, upon our institutions and physicians the necessity of keeping these women under a longer period of observation than has hitherto been the case, and, on the other hand, impressing upon the patients and their families the necessity and advisability for such supervision. A prolonged period of education may be necessary to accomplish this desirable end, but what has been accomplished in the domain of the contagious diseases, of cancer, of venereal disease, and other conditions, can likewise be duplicated in our obstetric practice. The survey of the situation which I have previously referred to, shows that in so far as maternity hospitals are concerned, great variation oceurs as to the extent to which postpartum observations are carried out. It is unnecessary to refer to specific institutions, but it was found that in many instances patients were dismissed in from ten to fourtcen days aftcr delivery without any definite instruction to return for subsequent observations. In other cases, the social service workers or follow-up nurses visited the patients in their homes in conjunction with the work done with the babies. It is, of course, a difficult matter for large institutions to maintain a sufficient staff of follow-up nurses to see all 
their cases, especially those living at a distance from the hospital, and, as already stated, it is a difficult matter for many of these patients to make personal visits to the hospital for examinations, but it ought to be possible to overcome these difficulties in most instances. Recommendations cannot be made in a general paper of this kind that would be suitable for individual institutions, and this matter must be left to the indications demanded by each particular ease. Hospitals with patients residing in their immediate vicinity ought not to have any difficulty in bringing them back for subsequent observation on stated days, when a clinic in charge of a physician could provide for the necessary examinations. This is excellent training for the younger men who would learn by repeated observation on the same patient the course of involution after labor and other postpartum conditions. Many of the simpler lesions ean be immediately corrected and those of a gross character kept under observation for possible future operation.

Such reformation of the accepted routine of obstetric hospital facilities as I have suggested will undoubtedly mean in most eases additional equipment and services that hospital managers may find it difficult to acquire under present conditions. But if it is the privilege and duty of our specialty to supervise the process of gestation from the time of conception through the delivery, this must also include the entire puerperal period, and a revised conception of the length of the latter beyond the usual ten days must be made to prevail.

Hospital standardization is the cry of the hour and in so far as this applies to obstetric institutions, it must be made to take cognizance of the fact that responsibility toward the recently delivered woman does not cease with her discharge on the tenth or twelfth day, and the shortcomings of institutional work apply with equal force to private practice.

There is another phase in discussing the question of appropriate and longer postpartum care to which in conclusion attention may be directed. Sociologists have seen, perhaps before the medical profession, the advantage of proper and more prolonged care after childbirth and have sought to attain this end through the medium of compulsory maternity insurance developed under state auspices. That the working classes might benefit by a scheme whereby a period of recuperation after labor could be secured is a question that must be given serious consideration, and much as we may have in general revolted against all plans of compulsory state health insurance thus far proposed as too paternalistic, socialistic and un-American, some modification of such plan may prove a desirable means of lowering the morbidity and mortality of childbearing. The subject is one that the profession may well consider from the standpoint of conslruclive ralher han destruclive crilicism.

During the last decade the development of standards for prenatal care has marked a great advance in our specialty in which we were led or groaded, perhaps, by certain lay influences, but in conclusion I may venture a prophesy and hope that the next decade or two will witness an equal acceptance of the fact that more prolonged and studied observation of the postpartum period is a part of the responsibility which as conscientious physicians we owe to our patients.

23 EAST NinetY-THIRd STREET.

(For discussion, seo p. 200.) 